\title{
Analysis of training accompaniment needs through prediction models assisted by machine learning
}

\author{
AKOUL $^{1}$ Mustapha, LOTFI ${ }^{2}$ Saïd, RADID $^{3}$ Mohamed
}

1. Observatory of Research in Didactics and University Pedagogy (ORDIPU), Faculty of Science of Ben M'sik, Hassan II University of Casablanca, BP 50069, Ghandi, Morocco. Mail: akoulmustapha@ gmail.com

2. Loboratory in Educations Sciences and Training Ingeneering. Assessment in Physical Activity and Sport (LMSEIF); (ESSBAP) Normal Superior School (ENS), Hassan II University of Casablanca, BP 50069, Ghandi, Morocco. Mail: lotfisaid@gmail.com

3. Laboratory of chemistry of materials in Ben M'sik Faculty; Hassan II Casablanca University; Morocco. Mail: m.radid@gmail.com.

\begin{abstract}
The purpose of this study is to analyze tendencies in the needs of students in accompaniment in a perspective of prediction of the measures to be taken during the training. This approach consists in measuring, with adapted prediction models, the tendencies of accompaniment needs in three areas of competence of the training: competencies practices, written competencies and oral competencies. To this end, the accuracy of the models in these three areas of competence must be verified in order to classify their prediction parameters. In a first step we used data modeling of machine learning with data partitioning, 70\% learning, 30\% testing of all data. Then we compared the predictive models (SVM, Neural Network, Bayasian Network, CART, CHAID, C5) using the global precision index. This allowed us to select the best model based on its accuracy performance in the three areas of expertise already mentioned.

Three models were selected among the six explored for their levels of accuracy in the three areas of expertise. The accuracy performance of the prediction models is therefore distributed as follows based on the domains: Practical skills (Neuronal Network) with an accuracy percentage of $68.66 \%$; Written skills (CART) with an accuracy percentage of 95.184\%; Oral skills (Bayesian Network) with an accuracy percentage of $66.6 \%$.

Prediction fields are defined from these analyses, containing a set of statements delineating the use of 7 predictors for the domain of practical competencies, 8 predictors for the domain of written competencies and finally 7 predictors for the domain of oral competencies.

These determined predictors are therefore the assets for our decisions regarding the design and implementation of possible support systems for the regulation of training.
\end{abstract}

Key words : Analysis, Accompaniment, Competencies, Prediction, Models,MachineLearning.

\section{INTRODUCTION}

Technology, science, and learning have often had causal relationships where innovative acquisitions in this field are constantly the result of a particularly technological expansion.

Indeed, the American psychologist Skinner. B.F. in the late 1950s, developed a "teaching machine". The latter is a mechanical device on which children activate a joystick to see the answer to an exercise and check whether they have found it, each child being able to move forward at a pace more or less adapted to answer the questions.

Then, gradually with the emergence of computers, "intelligent tutors" appeared in research laboratories from the 1970s onwards. The aim was to guide and assist learners in carrying out the tasks to be accomplished. As early as the 1990s, especially in the United States, this type of device was used in middle schools and high schools, particularly in the context of so-called technological learning. These virtual tutors have distinguished themselves exclusively in disciplines such as mathematics, physics and computer science.

At present, the analysis of statistical data for the purpose of readjusting learning or regulating teaching methods also has a crucial and interdisciplinary predictive value. These predictive analyses are no longer just the agitation of domains associated with mathematical logic. They are becoming more and more widespread in several domains, including education and training. Often at Western universities and in Moocs (Massive Open Online Course) where there is sufficient information about the students. This makes it easy to identify interest in course materials, attendance at the university's documentary instances. Also the attendance on the courses, the results obtained and 
the discussion forums, or even the nature of the questions posted on these forums and the links with other learners.

To this end, we can make predictions by generating scenarios of regulatory actions. This on the basis of the previous observations by identifying who has the greatest possibility among the students to validate or not its modules at the end of a semester. Or even detect those who risk losing their bearings and eventually dropping out.

As a result, rather than identifying a student who is likely to find himself in great difficulty, the sooner we can offer him an optimized remediation solution, in the form of targeted support based on the constraints shown. The proactive value of this approach gives it its relevance in the training context but also in a perspective of global monitoring of the student's professional or personal trends.

It is in this sense that we will develop this work of "predictive analysis" which aims to apply this method to classify and list the constraints and resources of our study population in three areas of training skills: practice, written and oral. This with the aim of implementing an optimal support system elaborated on the basis of the knowledge resulting from a reliable and valid instrumental practice.

Indeed, this systematic prediction approach will be our decision-making tool towards a real optimization of the different stages accompanying the target population. These quantitative analyses developed by the "predictive models" will not be blindly explored by the laws of reflexive hindsight, leaving room for a qualitative analysis based on an expert reading of the various data collected.

Our discussions at the end of this article will demonstrate the limits of this use in order to make its results more relevant to the contributions made in this work.

\section{CONCEPTUEL FRAMEWORK}

This theoretical framework can be part of a preventive decision-making model showing the relationship between the individual decision of the student who chooses a device and the institutional decisions of his host institution proposing support devices. Techniques to assist preventive decisionmaking in a changing environment can generally be divided into two main categories according to (Jardine et al. 2006): diagnosis and prognosis. Diagnosis deals with the detection and identification of abnormal dysfunctional behaviours, while prognosis aims at predicting these behaviours before their appearance and thereby ensuring permanent adaptation.

The present study extends this model to explain the evolution of adaptations or maladjustments of students during their initial training. It would therefore be possible to find typical indications or signs of prediction of a possible inadequacy of the rhythm and difficulty of the students' training. At the basis of the present study is therefore a postulate according to which: there are personal characteristics expressed and verbalized through the questionnaire administered to the students on their evolution in their study work. They are, to this effect, predictors of adaptation or not to training programs. If these predictors are explored and identified, their identification will be crucial for the development of optimized support systems.

The statistical study is the higher degree of quantification of objects which, even at a rudimentary level, makes their representation more accurate, more precise, more impersonal, less dependent on the subjectivity of the observer (M. Bibimoune, S. Rigori, L. Ji, E. Rappos, S. Robert, 2016). A measure is a convention, but a convention that only makes sense in its application to objects that it helps to define, and whose results are binding on all (Pita. C and Juan. C, 2015).

To this end, forecasting obeys this rule, insofar as it can be considered as an activity that measures what can be anticipated and predicted. It is therefore to predict or announce what is to happen either by intuition, or by unquestionable rules, or by supposition or reasoning associated with highly developed algorithmic logical estimates (Hayashi. Y., Bourdeau. J., Mizoguchi. R. 2009).

In other words, the requested forecast consists in estimating what will happen after a moment $t$, based on knowledge and on observations prior to this moment. Thus, in medicine, diagnosis, which consists in associating symptoms, observed at the moment, with the pathology at that same moment, is not a matter of prediction. On the contrary, prognosis, which consists, on the basis of the same information, in predicting the future evolution of the pathology and of the patient, is a matter of forecasting.

The search for effectiveness and efficiency was for a long time the ultimate "slogan" of all training programs that were intended to be qualitative. The population of a given training program would be transformed from the targeted quality, if it manages to properly follow all its curricular steps. We express here the chances of adaptation to the students' programs, which is an essential element in the development of the training project.

Indeed, from the very first stones in the edifice of a training program, we think about optimizing the difficulty that the trainees will have to overcome in their curriculum. This informed reflection must undoubtedly be based on a rational forecasting model.

Numerous research findings in university pedagogy on the factors associated with success or failure attempt to relate the particular traits of students entering higher education to their possible academic performance and their global adaptations in this new environment of their training, (De Ketele, J.M. 2010). It is known, for example, that a student's positive self-representation or the personal character that comes from his or her appetite for the decision to enter a field of study are important 
predictors of his or her subsequent success in the training program (Romainville. M, 1997).

In a forward-looking report from Stanford University as part of a 100-year program to study Artificial Intelligence (AI) in all its forms of impact on our lives. Researchers predict an increased presence of intelligent tutors in assisting teachers (Stone \& al. 2016). AI has already entered our daily lives, if only on the Internet, where it is widely used in advertising. The first tests of autonomous cars are also an expression of interest in AI. Google's project of "remotely-assisted" guided vehicles is ahead of the game.

On the other hand, we can also anticipate attempts to implement it in all spheres of life, including the field of education and training. Consequently, education is no exception in this great movement and we can already question the impact it will have on the landscape of education and training as a new approach to the production of knowledge.

Indeed, by collecting school and academic data and then combining it with students' acquisition habits, certain algorithms will be able to shape customized training programs and subsequently promote a diversification of the pedagogical offer. A way to reduce the failures of novice students' missteps in the university environment.

To this end, we can shape a program that is capable of grouping students according to the working methods that are most effective for them in a very short time. This approach, which in the past consumed a lot of time in observation, data compilation and statistical calculations, can be optimized by AI (Greenhow. G., Robelia. B., Hughes. J.E. 2009). It would therefore make it possible to increase the impact of teaching on learning and the adaptations planned in a training course. We can also design tailor-made accompaniment systems in which students will find their perception of learning to build themselves in a pertinent way.

In this context, we are far from a substitution, but rather a consolidation of the importance of the teacher with the students. While some situations of failure may be unavoidable in cases where personal circumstances to poorly adapt the desires of the learner to the proposed training. Many of them could be avoided by early detection, which would lead to more attentive and personalized reframing and follow-up. (Bovo, Sanchez, Héguy, Duthem, 2013).

It is for this objective of "early detection and attentive and personalized reframing" that we want to use this preventive method, which is based on the principle of "automatic learning", which consists of predicting a phenomenon based on past observations. It seeks to discover significant correlations in an association of data for the purpose of creating a predictive model of expectations and will even serve as a guide for decision making thereafter.

This method, also known as Machine Learning, is inseparable from artificial intelligence. It consists of using data relating to a target phenomenon under study to establish a scientific model to answer specific questions.

The main idea behind Machine Learning applied to student knowledge in a purely academic context is therefore to establish predictive analyses of their global behaviors, in order to design measures and actions optimized to make real decisions on the future of students during their training.

On the other hand, the exploration of Artificial Intelligence (AI) is put on the rise in training and education, and we cautiously tolerate its application in the field of support for students in training. In this regard, we are advancing the Intelligent Accompaniment Device (IAD), which can be summarized in a systemic model: that of designing, developing, implementing and evaluating (Bourdeau. J and Grand-bastien. M, 2011).

Predictive algorithm models will provide the perception of the meaning of the choices that can be made regarding support systems. As a consequence, these optimized support systems must be personalized and adapted to the specific needs of each student according to his or her training program. A system will be all the more useful if it is accessible to all in variety, especially in terms of cost and additional time involved in its use, if it is of high added value, especially for the preparation of the best adaptations, and if it is congruent with the student's reception structures, i.e. it does not imply a fundamental modification of his or her habits and student activities (Gurtner, J. \& Zahnd, J. 2003).

\section{METHODOLOGY}

\subsection{Participants}

The profiles of the students who constituted the sample of this study is heterogeneous on the physical profiles, as for the types of previous training followed. There were 147 student volunteers with an average age of $(17 \pm 21)$ years $(\mathrm{F}$ $\mathrm{n}=53 ; 36.1 \% ; \mathrm{M} \mathrm{n}=94 ; 63.9 \% ; \mathrm{n}=147 ; 100.0 \%)$. They were pursuing training in two different streams but affiliated to the same department at the "Ecole Normale Supérieure Casablanca". Hassan II University. This quantitative survey was conducted in 2018 on the basis of knowledge from questionnaires. Validated on a small scale.

\subsection{Description of the data}

We used all the individual data from the questionnaire sent via Google Forms for the 147 students. This allowed us to retrieve the answers in a short time. The corpus of data is collected on Excel Microsoft Office 2013.

Within the framework of a scientific approach to forecasting, we limit ourselves to a rule-based approach or systematic reasoning of Machine Learning Data Modeling (MDAM). The use that we target through this will focus on the prediction of 
the future of student behaviors based on a set of feelings expressed during the answers to the questionnaire.

This quantitative survey was carried out in 2018 on a knowledge base derived from a questionnaire administered to students during their training. The knowledge representation was obtained from the data using Microsoft Office Excel. The SVM, Réseau Neuronal, Bayasien Network, CART, CHAID and C5 software were also our tools for exploring the responses obtained at the end of their collections.

\section{RESULTS}

\subsection{Verification of the percentage accuracy of predictive analysis models}

In order to achieve the best possible accuracy of the different analysis models, we verified their performance on the different competencies areas (practical, written and oral) Table. 1. Algorithmic percentages vary according to the areas of competence. The Bayesian Network had the highest score in oral competencies $(66,667 \%)$. The Neuronal Network showed the best percentage accuracy of all other models tested in the analysis of the practical competencies domain, i.e. $(68.66 \%$ accuracy).

And finally for CART. CART showed the most accurate percentage in the Writing Competencies domain (95.184\% accuracy). This preliminary operation will guarantee us the best precision in the coherent emergence of the expected variables in order to predict the most relevant hypotheses to decide. The objective of this work is to design decisional algorithmic configurations that will predict the implementation of computerized intelligent diagnostic wizards of the best predictive models for the targeted support. While being aware of the limitations that may arise from its results when compared to another qualitative reading. We will later devote sketches of recommendations for an optimization of the chosen accompaniment devices.

\subsection{Partitioning and accuracy of competency domain predictors}

The "Machine Learning" carried out revealed significant but variable percentages based on the areas of expertise of the training. We thus measured the importance and correct partitioning of the predictors in table 1 below. This accuracy will enable us to use the most efficient model to predict and adopt a decision that is highly likely to lead to the success of the coaching systems used. These measures of compliance or accuracy are also a significant guarantee of the reliability of the measures of resolving decisions that we are going to take to develop the appropriate support system.
On the other hand, for each variable stabilized after classification in the field of competence, we have carried out a partition of their importance and priority in the handling and development of the inherent problem-solving systems. Table 1 below shows this organization, which will be explained by real decision trees that will function like maps of guidance in the genesis and development of the system.

Table 1 : Algorithm models explored in the prediction of accompaniment needs

\begin{tabular}{|c|c|c|c|c|c|c|}
\hline & \multicolumn{2}{|c|}{ Practical competencies } & \multicolumn{2}{|c|}{ Written competencies } & \multicolumn{2}{|c|}{ Oral competencies } \\
\hline Models & $\begin{array}{l}\text { Precision } \\
\%\end{array}$ & $\begin{array}{l}\text { Number of } \\
\text { predictors } \\
\text { retained }\end{array}$ & $\begin{array}{c}\text { Precision } \\
\%\end{array}$ & $\begin{array}{c}\text { Number of } \\
\text { predictors } \\
\text { retained }\end{array}$ & $\begin{array}{c}\text { Précision } \\
\%\end{array}$ & $\begin{array}{c}\text { Number of } \\
\text { predictors } \\
\text { retained }\end{array}$ \\
\hline C5 & 68.02 & 5 & 61.224 & 2 & 62.585 & 1 \\
\hline $\begin{array}{l}\text { Bayesian } \\
\text { Network }\end{array}$ & 68.02 & 7 & 61.224 & 8 & $66.667^{*}$ & 7 \\
\hline $\begin{array}{l}\text { Neuronal } \\
\text { Network }\end{array}$ & $68.66^{*}$ & 7 & 59.184 & 8 & 62.585 & 7 \\
\hline $\begin{array}{l}\text { Regression } \\
\text { Logistic }\end{array}$ & 63.26 & 7 & 59.864 & 8 & 65.986 & 7 \\
\hline CART & 59.18 & 7 & $95.184 *$ & 8 & 59.184 & 7 \\
\hline
\end{tabular}

4.3. Prediction of the need for coaching in practical competencies by the Neural Networks model

The practical competencies selected in predicting the need for coaching during training are seven predictors:

Leading a group on the sports field ;

Supporting intense strength exercises,

Support endurance exercises ;

Monitor the intensity of the practice sessions;

Progress in learning techniques ;

Respect time during practice;

Being accepted by others in the game ;

\section{Number of units: 7}

Resizing method for Covariates: Standardized The neural network is retained as the model giving the highest accuracy $(68.66 \%)$ among all the models introduced in the prediction of the need for coaching in practical skills whose parameters are represented in graph (Figure 1) and conditional probabilities (Table 1), and degree of importance of the predictors (Figure 3 ).

The output layer is set to a single dependent variable expressed by the need for coaching in two modalities (need for accompaniment, no need). Softmax was chosen as the activation function, and cross-entropy as the error function in the analyses. 
Table 2 : Percentage of correct incorrect predictions during the Learning Phase and the Test Phase.

\begin{tabular}{|c|c|c|c|c|}
\hline \multicolumn{2}{|c|}{ Identification of needs } & \multicolumn{3}{|c|}{ Forecasts } \\
\hline Sample & Observé & $\begin{array}{l}\text { Need to be } \\
\text { accompanied }\end{array}$ & No need & $\begin{array}{c}\text { Correct } \\
\text { percentage }\end{array}$ \\
\hline \multirow{3}{*}{ Learning } & Need to be accompanied & 18 & 24 & $42,9 \%$ \\
\hline & No need (Aucun besoin) & 11 & 48 & $81,4 \%$ \\
\hline & Pourcentage global & $28,7 \%$ & $71,3 \%$ & $65,3 \%$ \\
\hline \multirow{3}{*}{ Test } & Need to be accompanied & 10 & 8 & $55,6 \%$ \\
\hline & No need (Aucun besoin) & 3 & 25 & $89,3 \%$ \\
\hline & Pourcentage global & $28,3 \%$ & $71,7 \%$ & $76,1 \%$ \\
\hline
\end{tabular}

The global percentage of the Prediction by the neural network algorithm during the learning phase is $65.3 \%$ correct with an estimated duration of 0:00:00.02, so it increased to $76.1 \%$ during the test phase. The prediction is thus improved by $10.8 \%$. In other words, the percentage of incorrect predictions was reduced from $34.7 \%$ during the learning phase to $23.9 \%$ during the test phase.

The results showed that the neural network is formed by a masked layer with 6 number of units whose activation function is based on the Hyperbolic Tangent type (Figure 1).

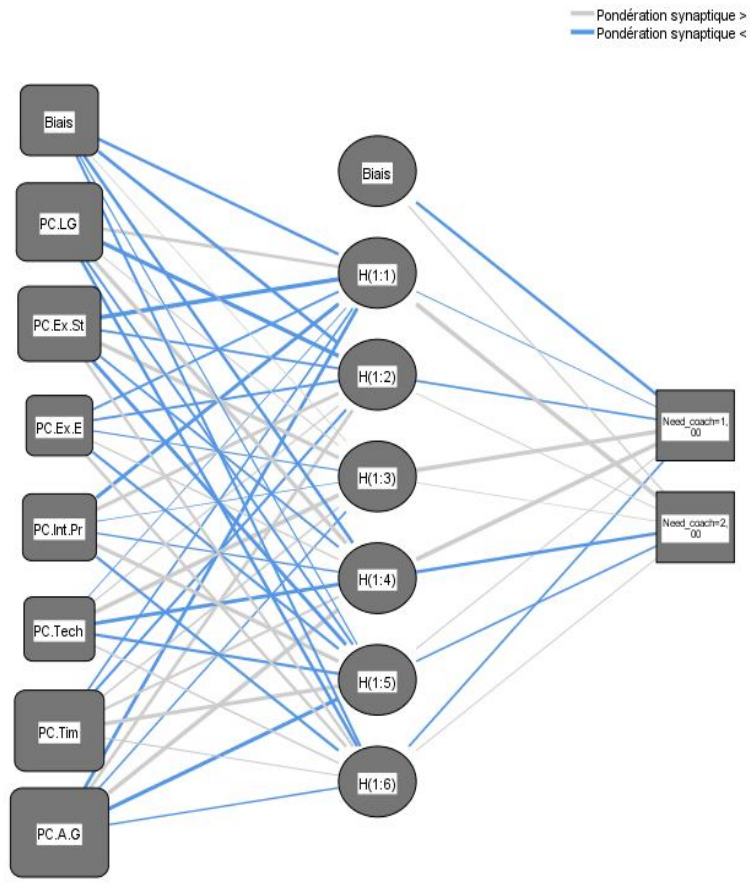

Couche masquée pour la fonction d'activation : Tangente hyperbolique

Couche de sortie pour la fonction d'activation : Softmax

Figure 1 : Hyperbolic Tangent type
Table 3 : Parameter estimates.

\begin{tabular}{|c|c|c|c|c|c|c|c|c|c|}
\hline \multicolumn{10}{|c|}{ Parameter estimates } \\
\hline \multirow{3}{*}{\multicolumn{2}{|c|}{ Predictor }} & \multicolumn{8}{|c|}{ Projections } \\
\hline & & \multicolumn{6}{|c|}{ Masked layer 1} & \multicolumn{2}{|c|}{ Exit layer } \\
\hline & & $\mathrm{H}(1: 1)$ & $H(1: 2)$ & $H(1: 3)$ & $H(1: 4)$ & $H(1: 5)$ & $H(1: 6)$ & [Need_coach=1,00] & [Need_coach=2,00] \\
\hline Entry & (Biais) & -317 &,- 411 & 007 &,- 394 & ; 142 & -262 & & \\
\hline \multirow[t]{7}{*}{ layer } & PC.LG &, 393 &,- 566 & 059 & .570 & -242 & -403 & & \\
\hline & PC.Ex.St & t,605 &,- 206 &, 540 &,- 216 & ;443 &, 313 & & \\
\hline & PC.Ex.E &,- 221 &,- 235 & -,132 & ,152 & -256 &, 359 & & \\
\hline & PC.Int.Pr &,- 450 &, 426 &,- 002 &,- 154 & ,475 & -281 & & \\
\hline & PC.Tech &,- 014 & ,141 & ,614 &,- 440 & -308 & 161 & & \\
\hline & PC.Tim &,- 196 & -246 &, 181 &, 246 & ,476 & , 087 & & \\
\hline & PC.A.G &,- 429 &, 416 &,- 178 & ,651 &,- 471 &,- 161 & & \\
\hline Masked & (Biais) & & & & & & & -370 & ,143 \\
\hline \multirow[t]{6}{*}{ layer 1} & $H(1: 1)$ & & & & & & &,- 021 &, 780 \\
\hline & $H(1: 2)$ & & & & & & & -192 & 023 \\
\hline & $H(1: 3)$ & & & & & & &, 595 & ,005 \\
\hline & $\mathrm{H}(1: 4)$ & & & & & & & ,681 &,- 383 \\
\hline & $H(1: 5)$ & & & & & & & ,068 &,- 189 \\
\hline & $H(1: 6)$ & & & & & & & -202 & 059 \\
\hline
\end{tabular}

The use of the Neural Network in the analysis of the variables related to practical competencies was carried out in two steps. First, a learning phase in which values were established for each of the network connections, then a use phase, in which the network was presented with an input of the variables to be studied and finally the calculated output of the $(\mathrm{H}(1: 1)$ to $H(1: 6)$ was given back to the network.

The parameters tested and estimated on the neural network of figure. 1 in machine configuration are explained in (Table 3).

The connection of these units, represented here as variables of the domain of practical competencies between them from $H(1: 1)$ to $H(1: 6)$, revealed the discrimination capacity of the NR obtained in the parameterization table (Table 3). The distribution of the values of the variables in automata (neurons), gave us the possibilities to determine the value of the estimation parameter.

Ex.F. Support intense strength exercises;

Ex.End.: Support endurance exercises;

AG: Being accepted by others in the game;

Int.Pr.: Monitor the intensity of the practice sessions;

AJ: Leading a group on the sports field;

Tch.: Progress in learning techniques;

Tps : Respect time during practice.

The main predictors retained from the analysis of the nueronal network model. The six predictors in the tree configured from their priorities in the choices. 
Table 4 : Level of importance of predictors of the need for coaching in practical competencies.

\begin{tabular}{lcc}
\hline \multicolumn{1}{c}{ Predictors } & Importance & $\begin{array}{r}\text { Standardized } \\
\text { Importance }\end{array}$ \\
\hline Leading a group on the sports field &, 174 & $70,5 \%$ \\
Support intense strength exercises &, 153 & $61,9 \%$ \\
Support endurance exercises &, 055 & $22,3 \%$ \\
Monitor the intensity of workouts &, 098 & $39,9 \%$ \\
Advances in learning techniques &, 081 & $33,1 \%$ \\
Manage time during practice &, 193 & $78,4 \%$ \\
Being accepted by others in the game &, 246 & $100,0 \%$ \\
& & \\
\hline
\end{tabular}

In the area of practical competencies, the analysis revealed 7 predictors with varying degrees of importance. Their scores, shown in Table 3, will enable us to rank them in order of preference during the implementation of the support measures targeted for the participating population. Support for fundamental endurance exercises" and time management during physical effort seem to be the two predictors of work to be reinforced in students based on the results of this loss. It is therefore convenient to design reinforcement and accompanimentwork for those competencies identified as fragile.

\subsection{Prediction of the need for coaching in} written competencies by the CART model

The predictive analysis chosen, also illustrates that in the area of written competencies, only $40.8 \%$ of the participants expressed the need for coaching in this area.

Indeed, these predictive analyses revealed the existence of a put variable "follow the writing instruction" expressed by $31.5 \%$ in node 4 in Figure.2, which is expressed as a need by participants in this competency area.

Finally, from the same analysis, another priority variable emerges, "Argue your answers with valid knowledge", expressed by $38.5 \%$ in Knot 3 (Figure.2).

To this end, support activities in this situation will be based on work that combines "the correctunderstanding of concepts, textual instructions and the meaning of a referenced scientific argumentation". This is a way that will allow us to hypothesize about the process of accompaniment to be put in place.

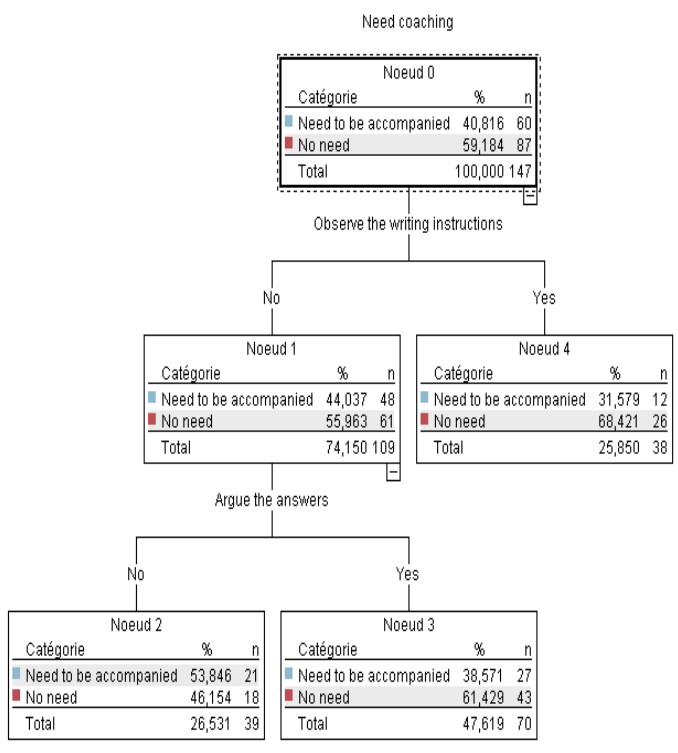

Figure 2 : Classification of Writing Competency Predictors

\subsection{Prediction of the need for support in oral competencies using the Bayesian Networks model}

The Bayesian network is selected as the model giving the highest accuracy of $68.02 \%$ among all the models introduced in the prediction of coaching in oral competencies, the parameters of which are graphical representation (Figure 1) and conditional probabilities (Table 1), and the degree of importance of the predictors (Figure 2). The results showed that the overall conditional probability of needing accompaniement found in our sample is 0.41 .

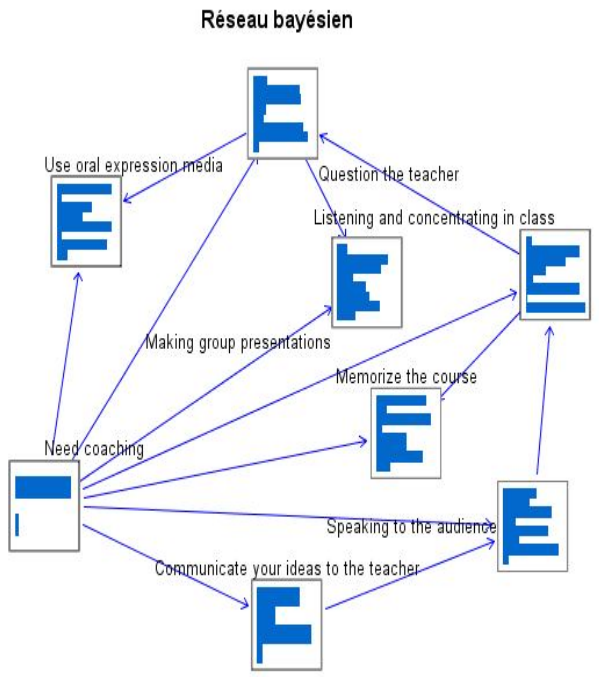

Figure 3 : Bayesian Network of Predictors of the Need for Oral Competencies accompaniement 
The oral competencies selected in predicting the need for accompagnement during training are seven predictors:

Listening and concentrating in class;

Questioning the teacher;

Making group presentations;

Memorize the course ;

Communicate your ideas to the teacher ;

Speaking easily to the audience ;

Use oral expression media.

These are the main predictors retained for the domain of oral competencies. They concern variants of students' skills during training.

Table 5 : Conditional probabilities and degree of importance of predictors of the need for accompaniment in the area of oral competencies.

\begin{tabular}{lclc}
\hline \multicolumn{1}{c}{ Predictors } & $\begin{array}{c}\text { Degree of } \\
\text { importance }\end{array}$ & \multicolumn{1}{c}{$\begin{array}{c}\text { Variable } \\
\text { Conditional }\end{array}$} & $\begin{array}{c}\text { Conditional } \\
\text { probability }\end{array}$ \\
\hline $\begin{array}{l}\text { Listening and concentrating } \\
\text { during oral exchanges in class }\end{array}$ & $0,1259^{*}$ & Addressing the audience & 0,34 \\
$\begin{array}{l}\text { Question and exchange with } \\
\text { the teacher }\end{array}$ & 0,0607 & $\begin{array}{l}\text { Listening and concentrating in } \\
\text { class }\end{array}$ & 0,40 \\
$\begin{array}{l}\text { Memorize lesson concepts } \\
\text { Interview and exchange with } \\
\text { the teacher }\end{array}$ & 0,48 \\
$\begin{array}{l}\text { Make group presentations } \\
\text { Communicate your ideas } \\
\text { appropriately to the teacher }\end{array}$ & $0,2341^{*}$ & $\begin{array}{l}\text { Listening and concentrating } \\
\text { during oral group discussions }\end{array}$ & $0,50^{*}$ \\
Addressing the audience & $0,1352^{*}$ & $\begin{array}{l}\text { Building group presentations } \\
\text { Us, }\end{array}$ & $0,53^{*}$ \\
$\begin{array}{l}\text { Use the media as a means of } \\
\text { oral expression }\end{array}$ & 0,1194 & $\begin{array}{l}\text { Communicate ideas } \\
\text { appropriately to the teacher } \\
\text { Question and discuss with the } \\
\text { teacher }\end{array}$ & $0,76^{*}$ \\
\hline
\end{tabular}

\section{ANALYSIS AND DISCUSSION}

\subsection{Practical competencies}

In the area of practical competencies, the analysis revealed 7 predictors with varying degrees of importance. The Scores obtained allow us to rank them in order of preference during the implementation of support systems. These are therefore priorities that will guide the choice of content and intervention strategies for the target students. Despite the identification of the seven predictors, the neural network model used showed a low need in this field of practical training.

However, "support for fundamental endurance exercises" and "time management during physical effort" seem to be the two work predictors to be reinforced in students based on the results of this loss. It is therefore convenient to conceive a work of reinforcement and accompaniment for these identified sub-competencies which are mainly related to practical knowledge based on physical and functional capacity in technical acquisitions.

\subsection{Written Competencies}

The CART model of predictive analysis opted for, shows that only $40.8 \%$ of the participants expressed the need for coaching in this skill area. The Predictive Analyser revealed the existence of a put variable "follow the writing instruction" expressed by $31.5 \%$ in node 4 in Figure.2, which is expressed as a priority need in this skill area.

Also emerging from the same analysis is another priority variable, that of "Supporting responses with valid knowledge", expressed by $38.5 \%$ in Node 3 (Figure.2).

To this end, accompaniment activities will have to target the understanding of instructions and their interpretation according to the trainers' expectations. The discrepancy between the baseline situation as a training objective and the students' progress in this area suggests that even if the predictors are small, their usefulness is put to good use and will be subject to a coaching system based on the initiation of professional writing. The working hypotheses that emerge for the coaching activities in the case of the field of written competencies will thus be based on thematic work with the development of specific contents that will establish links between "the correct understanding of concepts, textual instructions and the perception of a referenced scientific argumentation" the score achieved $38.5 \%$ on node 3 (figure 2).

\subsection{Oral competencies}

For this domain of competencies, the analysis has brought out new data relating to the specificity of support in this domain. Indeed, conditional probabilities have been identified according to the predictors defined with disparate degrees of importance, leaving room for further judicious choices in the coaching of students. The need for coaching in the area of oral competencies is clearly expressed by respective degrees of importance, namely: "Addressing the audience" with 0.2685 and "Making group presentations" with 0.2341 (Table 5).

Speaking, especially in front of an audience, is a privileged dimension of the teaching profession, which is why enthusiasm is still high among participants. To this end, the accompanying activities under the conditions observed will extend to tasks that will constitute coherent links between "the technical use of multimedia and the development of appropriate postures in front of the audience". This is the argumentation for the definition of the hypotheses of the accompanying device to be implemented.

From another, more global point of view on the approaches of the predictions explored during the three models. We are going to stabilize on some predictive indices open to the accompanying measures for these participants. We will explain them on the basis of a breakdown into three sub- 
groups of special needs. This is what will guide our choices for future support measures that are more convenient for the profiles identified.

In the first subgroup, students who have expressed total satisfaction with the interest they give to the training modules and the content they compose, look high enough to succeed in their years of training. They therefore have no detrimental difficulties in continuing the training program. They also score very well on the academic results obtained at the end of the first semester of training in the first year. This category of identified students, also have a perfect confidence in their evolutions in the construction of the various competences grouped and chosen for this study: (Written Competencies C.E, Oral Competencies C.O, Practical Competencies C.P).

The second group brings together students at risk, but close to a global adaptation. For them, it would undoubtedly be desirable to offer measured help. It is this population that will be the target of our support systems. The heterogeneity of the group is also put into evidence by the fact that it is likely to be very heterogeneous : according to the results obtained, there are very disparate profiles. The lack of control of time management was also a cause expressed in their answers to the questionnaire. By identifying these areas for improvement, the methodological support and time management systems in the training could be a remedial measure.

In short, a better knowledge of the group at risk will guide the accompanying interventions, which will be as diversified as the student profiles identified. The algorithm for predicting progress and the measures to be undertaken that we have explored above for the three areas of competence (C.E, C.O, C.P) is a means of framing, or even optimising, the choices of target populations and the appropriate measures.

The third group is made up of students who have demonstrated major shortcomings and whose chances of success at the end of the year are certainly very limited. Experience shows that the problems specific to this group go well beyond the framework of learning difficulties (Cathy Perret, 2018): poor choice of studies, difficulty in managing their new freedom, etc. (Cathy Perret, 2018). Often, these students are no longer physically or psychologically in training. Sometimes, this student profile is already perceptible at the beginning of the academic year. For this purpose, a possible orientation early in the year may offer them adequate adaptations. Hence the usefulness of setting up accompaniment system that integrates the context.

\section{SUGGESTIONS}

The proposed analysis must be accessible and debatable, in order to be eventually refined to improve its predictive value. Prediction errors, concretized by the discrepancies between the predictions of "predictive" models and experimental observations, play a fundamental role in the tasks of validation and improvement of the choices of accompanying interventions. The validation of the results is therefore a very important step, but also a very difficult one in that it will require sharing and consultation. To this end, we intend to share it by exploring it further in another context of pedagogical supervision particularly related to training in teaching professions.

On the other hand, independently of the validity of the predictions, we will also question the effect of their communication. A phenomenon abundantly described in pedagogy would, in particular, be to be avoided: the Thorndike halo effect of prediction, i.e. the realization of the predicted things caused by the very fact of having predicted them cited by (Bressoux, P. 2018). Students and teachers are thus at risk of conforming to the predicted results. They risk working less because they are discouraged by these predictions, communicated implicitly by their producers. In other words, serious thought must be given to the need, on the one hand, and the way, on the other hand, to communicate the predictions to the actors themselves. A temporality is necessary to act pertinently in this process of information sharing, which requires an optimization without which the stakes of the prediction may be distorted. We support at the end of this reflection that, although it may be premature to teach or support students by relying on the "arsenal" of AI as pedagogical tools of the future. We recommend a "Predicted Systematic Accompaniment" (P.S.A.) with four priorities based on fundamental questions that should be of great pedagogical utility at the university and more specifically in training. This is in order to identify quantitative indices that, with the expert intervention of human beings, are likely to produce real qualitative knowledge:

Awareness of data and the ability to construct and manipulate large amounts of data. And to this end, to set up database grouping cells that reinforce credibility and facilitate sharing with other actors.

Understand the randomness and acceptance of the inconsistency where models cease to be deterministic. This will be a necessary lever for the assimilation of uncertainty in these kinds of activities, which can only improve the effectiveness of the initiators of action research in education.

Build competencies that enable individuals to solve problems using algorithms where choices based on targeted predictions in the cited competence areas allow the concerted manipulation of the tool to decide on suitable routes to grouped profiles according to needs.

Adopt critical thinking adjusted and convenient to digital use in education, training or more in accompaniment. This is another way of continuing to question our own humanity for the purpose of 
understanding the changes brought about by these new practices, which should not be an end in itself. For these predictive analyses, as diverse as they may be, must not escape the right measures of reason and human consciousness. Researchers, trainers or students, they will never be replaced by the artificial intelligence algorithms that are beginning to invade the fields of forecasting in education and training.

\section{CONCLUSION}

According to this demonstration, the implementation of accompaniment devices requires a systemic approach with a numerical use that facilitates the manipulation of predictors. The predictive models adopted in this study depend on the performance of the precisions obtained in the three areas of training competencies. As a result, for each predictive model there is an appropriate competency domain. This will allow the identification of a limited but targeted number of priorities to be targeted by the envisaged accompaniment device.

As a result, the participants targeted by this experimentation show shortcomings emanating from the nature of the training they conduct. They reveal a very respectable level of practical competencies, with no uncertainty or deep-seated fears in this area, and the current state of their preparation does not require further accompaniment or support.

On the other hand, for the two other competence domains $\mathrm{CO}$ and $\mathrm{CE}$ (oral and written competencies), the predictive analysts strongly recommended support and accompaniments measures by specifying the areas of competence to be strengthened.

The practical competencies domain was a need revealed in the results. Consistent in the students' perception of what support and accompaniment would be required. For it is one of the important components of the profession of the future PSE (physical and sports education) teacher.

Indeed, the group's mastery in physical activity will only be achieved through its adequate postures, its global actions and its ability to clearly express what is aimed at by an effective practice. The good management of the social space where the practices will take place and the adoption of positive behaviors with others will be a means of mastering in accordance with the perception of the team's "manager".

The working hypotheses that emerge for the support activities in the case of written competencies will be based on a thematic work that will weave links between a correct understanding of the notions, textual instructions and the meaning of a referenced scientific argumentation. Another essential requirement of the global competencies is that of teaching these students at the beginning of their professional training.
On the other hand, on the field of oral competencies. The mastery of the oral, especially in front of the public, is a privileged dimension in the teaching profession, which is why there is still great enthusiasm for the participants to express demands and needs for the profession they are preparing for. We can also conclude accompanying activities based on the conditions observed and which will constitute coherent links between: the use of multimedia techniques and the development of adequate postures in front of the audience.

To this end, and based on this understanding of the facts, we can qualify as "meticulous". Artificial intelligence has a great potential for improvement for decision making in the training environment. The successful implementation of these prediction systems requires careful attention to detail, especially by using the right method and the right tool for the purpose of the predictive system, and this during the knowledge representation phase. This is done by paying attention to the right details that prepare the necessary investigation ground for the use of the chosen predictive system.

As a result, the awareness of all the actors, teacherresearchers, students and educational administration to the interesting attributions of this predictive approach. Thus, it will have to be formulated in terms of intelligent tools for well-founded decisions in conformity with the contexts of the target training courses.

In actual practice, the "Learning Machine" is for AI to model phenomena based on data collected regardless of their size. The goal of this modeling is ultimately to be able to make decisions, which is a simple pedagogical act to complex strategic measurement. We do not claim, in the light of this experience, to move towards a totally objective use of this analysis tool. The exploratory instruments of artificial intelligence in educational environments are rare and even less active in producing real knowledge (AI) as predisposed to generalization as those of the emerging pedagogy of action research with learners who interact in spontaneity but also in the formalism of the educational environment which is becoming increasingly digitalized.

\section{REFERENCES}

1. Andrew KS Jardine, Daming Lin, DraganBanjevic : Un examen des diagnostics et pronostics des machines mettant en œuvre la maintenance conditionnelle; Elsevier Ltd. Volume 20, Issue 7, Octobre 2006, pages 14831510.

2. Bovo, A., Sanchez, S., Héguy, O., and Duthen, Y. «L'apprentissage automatique comme base du suivi d'élèves et de l'amélioration de formations ». In Actes de la Journée EIAH\&IA 2013. (Cité en pages 38, 164 et 257.)

3. Cathy Perret. C and Henry. M, « Rebondir dans la même université après un échec en première année de santé : les stratégies étudiantes dans le 
cadre d'un dispositif institutionnel de réorientation ", L'orientation scolaire et professionnelle, 47/2 | 2018, 2021. URL : http://journals.openedition.org/osp/6153

4. Greenhow. G., Robelia. B., Hughes. J.E. Learning, Teaching, and Scholarship in a Digital Age. Web 2.0 and Classroom, Educational Researcher 2009, n³8, p. 246-259.

5. Gurtner, J. \& Zahnd, J. « L'accompagnement pédagogique : Un incontournable de la formation professionnelle continue à distance » 2003. Distances et savoirs, vol. 1(4), 459-470.

6. Hayashi. Y., Bourdeau. J., Mizoguchi. R. «Using Ontological Engineering to Organize Learning/Instructional Theories and Build a Theory-Aware Authoring System », IJAIED ; 2009 ; Vol. 19 n², p. 211-252.

7. Jacqueline Bourdeau, Monique Grandbastien. «La modélisation du tutorat dans les systèmes tutoriels intelligents ». STICEF (Sciences et Technologies de l'Information et de la Communication pour l'Éducation et la Formation), ATIEF, 2011, 18, 14 p.

8. Jardine, A, et al. «A review on machinery diagnostics and prognostics implementing condition-based maintenance $\gg$. Mechanical Systems and Signal Processing 20.
ScienceDirect ; Volume 20, numéro 7, octobre 2006, pages, 1483-1510

9. Jean-Marie De Ketele. « La pédagogie universitaire : un courant en plein développement », Revue française de pédagogie, 172 | 2010, 5-13.

10. M. Bibimoune, S. Rigori, L, Ji, E, Rappos, S. Robert; " Analyse prédictive de séries temporelles », Bulletin SEV/VSE 10/2016, pp. 41-44

11. Pita Castro, Juan Carlos ; «Social gravities and artistic training paths : the artistic vocation viewed through the prism of the concept of temporal form of causality ». 2015. European Journal for Research on the Education and Learning of Adults, 6.

12. Romainville Marc. « Peut-on prédire la réussite d'une première année universitaire ? ». In : Revue française de pédagogie, volume 119, 1997. L'éducation préscolaire. pp. 81-90 ;

13. Stone P \& al. " Artificial Intelligence and Life in $2030 »$. One Hundred Year Study on Artificial Intelligence : Report of the 2015-2016 Study Panel. Stanford University.

14. Bressoux, P. «Comment se fabrique le jugement des enseignants ?»; Revue : Regards croisés sur l'économie, de la page 15 au 23. 2018, https://doi.org/10.3917/rce.022.0015. 